\title{
FUNDAÇÃO DE ASSISTÊNCIA INTEGRAL À SAÚDE/HOSPITAL SOFIA FELDMAN: UMA EXPERIÊNCIA DE ADMINISTRAÇÃO FLEXÍVEL?
}

\author{
Marilia Alves* \\ Heloisa de Carvalho** \\ Marta Araújo Amaral***
}

\begin{abstract}
ALVES, M.; CARVALHO, H.de; AMARAL, M.A. Fundação de assistência integral à saúde/hospital Sofia Feldman: uma experiência de administração flexível?. Rev.latino-am.enfermagem, Ribeirão Preto, v. 7, n. 4, p. 5-11, outubro 1999.
\end{abstract}

O presente trabalho teve como objetivo traçar um paralelo entre a experiência administrativa do Hospital Sofia Feldman e a teoria de gerência flexivel proposta por MOTTA (1991) e MÉDICI \& SILVA (1993). Descreve, também, elementos inovadores de integração da instituição com a comunidade: mãe substituta, ombudsman e trabalho voluntário sistematizado da Associação Comunitária dos Amigos e Usuários do Hospital Sofia Feldman. A coleta de dados foi feita através de roteiro de entrevista semiestruturada, aplicado a funcionários de diferentes setores, procurando conhecer a percepção dos mesmos sobre o modelo gerencial adotado. Os depoimentos apontaram características de administração flexível no hospital, porém, permeada de traços da gerência clássica.

UNITERMOS: administração hospitalar

\section{INTRODUÇÃO}

No decorrer do Século XX, várias transformações de ordem econômica, social, cultural e tecnológica foram observadas na sociedade, com reflexos nas organizações, o que provocou mudanças nas filosofias de administração, controle e gestão da produção de bens e serviços. As transformações nas organizações de saúde, principalmente as tecnológicas de custo elevado, nem sempre são acompanhadas de novas formas de gestão, capazes de promover a satisfação dos profissionais e de responder às demandas dos clientes.

As dificuldades internas das organizações, em seus múltiplos aspectos, provocam a queda na qualidade dos serviços oferecidos. É freqüente a insatisfação dos clientes, que, além de não receberem o tratamento de que necessitam, não têm acesso às informações internas que possam explicar o aparente descaso para com seus problemas e aflições.

A comunicação, entre as organizações de saúde e usuários, é ineficiente o que dá margem à interpretação de que a clientela não é atendida em suas necessidades somente por má vontade ou incompetência dos trabalhadores de saúde, responsáveis, em última instância, por atendê-la em ambulatórios, postos de saúde e hospitais. Não se pode negar que esta seja uma realidade em alguns serviços ou que se aplique a alguns profissionais, mas generalizar a questão parece-nos injusto para com os profissionais responsáveis e comprometidos. Mas o fato dos usuários não terem sequer conhecimento das normas de funcionamento das organizações, da carência freqüente de pessoal e material e da demanda por serviços maior que a capacidade de atendimento, dentre outros fatores, freqüentemente, resulta em sentimento de desconsideração para com os seus problemas.

Há, portanto, um grande descompasso entre o que prevê as novas formas de gestão contemporânea e as formas de gestão adotadas pelos serviços de saúde. Parece não haver, ainda, nas organizações de saúde maiores preocupações com a competitividade e ocupação de novos mercados, porque sobram clientes, principalmente quando se trata de serviços destinados aos menos favorecidos economicamente. Este vasto contingente de

\footnotetext{
* Mestre em Administração. Doutora em Enfermagem. Professora Adjunta do Departamento de Enfermagem Aplicada da Escola de Enfermagem da Universidade Federal de Minas Gerais

** Mestranda em Enfermagem Professora Auxiliar de Ensino do Departamento de Enfermagem Aplicada da Escola de Enfermagem da Universidade Federal de Minas Gerais

*** Mestranda em Enfermagem. Professora Auxiliar de Ensino do Departamento Materno Infantil e Saúde Pública da Escola de Enfermagem da Universidade Federal de Minas Gerais
} 
clientes não desperta o interesse das empresas de saúde, que complementam os atos dos serviços públicos, sendo precariamente remunerados através do Sistema Único de Saúde (SUS). A grande massa de desassistidos que bate diariamente às portas dos serviços de saúde, na maioria das vezes, não consegue sequer uma consulta médica, que deveria ser uma parte da assistência à saúde e não a sua única expressão. Assim, para os dirigentes da área de saúde mais comprometidos com a assistência à população, uma questão crucial se coloca: como atender às necessidades dos usuários do serviço de saúde e dos trabalhadores, garantindo ao mesmo tempo, a sobrevivência da organização?

Algumas sinalizações, embora tímidas no campo prático, começam a aparecer principalmente na área gerencial, onde a rigidez dos modelos tradicionais vem sendo gradativamente substituída por novas formas, mais condizentes com o momento atual.

MÉDICI \& SILVA (1993), referindo-se às mudanças nos paradigmas gerenciais do Século XX apresentam três momentos distintos e seqüenciais vivenciados pela sociedade: o taylorismo, do final do século passado até a década de quarenta, caracterizado por intensa divisão do trabalho, separação entre concepção e execução, padronização da produção e ganhos de produtividade baseados na racionalização e melhor aproveitamento de tempos e movimentos no processo de trabalho; o fordismo, da década de quarenta até meados dos anos setenta, caracterizado pela introdução de novos elementos de organização e gestão, como incorporação da produtividade aos salários ampliando as discussões democráticas, inovações tecnológicas e barateamento da produção, preocupação com o bem estar dos empregados, livre negociação dos salários e condições de trabalho sob o poder dos sindicatos, contrapondo-se à rigidez do modelo taylorista, concessão de incentivos e benefícios e introdução da discussão sobre incentivos motivacionais e a Administração Flexível que se inicia na segunda metade da década de setenta, sinalizando o esgotamento dos modelos anteriores e a necessidade de novos estilos e práticas de gestão, mais condizentes com as necessidades de flexibilização do momento, a nível mundial.

O contexto de crescente globalização da economia exige, como requisito para modernização de empresas públicas e privadas, a adoção de modelos compatíveis com a realidade atual, que possa atender adequadamente às necessidades dos usuários e trabalhadores de saúde. A velocidade das mudanças experimentadas pela sociedade, com reflexos claramente perceptíveis nas organizações, culminaram com a adoção de princípios de administração flexível que pode ser compreendida como "o processo de gestão que leva a empresa a adquirir sensibilidade e capacidade de resposta, no curto prazo, para as alterações no ambiente externo, tais como demanda de clientes, as inovações tecnológicas cada vez mais constantes e imprevisíveis e as novas formas de concorrência" (MÉDICI \& SILVA, 1993).

As novas idéias são introduzidas, de acordo com MOTTA (1991), para reverter as práticas organizacionais baseadas na teoria clássica e visam uma gerência com maior descentralização das decisões, compartilhamento de autoridade, estrutura dinâmica com interdependência entre os serviços, podendo haver mudanças e adaptações contínuas conforme as necessidades ambientais.

MÉDICI \& SILVA (1993), para facilitar a compreensão dos fundamentos da administração flexível destacam, como importantes, as seguintes características: - o trabalhador é visto como uma pessoa criativa e inteligente, que participa das discussões de grupo, tendo um papel determinante na organização do trabalho e resultados;

- a capacitação e aperfeiçoamento de pessoal passa a ser um processo contínuo e permanente, nos postos de trabalho, em substituição ao treinamento dirigido tradicional;

- os salários e condições de trabalho passam a ser negociados, de forma flexível, em função da condição real específica de cada empresa, naquele momento;

- a empresa apresenta total visibilidade no que diz respeito às informações econômicas, financeiras e contábeis no momento da negociação;

- há redução dos níveis hierárquicos e as chefias participam do cotidiano do trabalhador, discutindo e aperfeiçoando o processo de trabalho e o produto final; - a empresa é mais sensível às exigências do mercado; - o controle da qualidade passa a ser feito em cada etapa do processo de trabalho, o que permite conhecer melhor as falhas e corrigi-las;

- a comunicação passa a ser essencial em todos os sentidos da hierarquia da empresa;

- há diversificação e capacidade de mudança, no curto prazo, visando adaptações às exigências de mercado; e

- as estruturas administrativas sofrem mudanças, se tornando mais leves.

No entanto, a organização flexível de acordo com MOTTA (1991), não pode sobreviver na dependência absoluta de variações ambientais. Ela necessita de alguma regularidade estrutural para enfrentar as incertezas externas através de estruturas simples, dotadas de flexibilidade, em contraste com os modelos complexos e imobilizadores adotados por algumas empresas. As propostas organizacionais se assentam em fronteiras menos nítidas da autoridade e da hierarquia, buscandose a simplicidade através de maior descentralização e sistemas de informação mais diretos e acessíveis, para o aprimoramento das comunicações internas. "Trata-se de um modelo de organização descentralizada, com unidades 
autônomas que refletem, a princípio, o todo organizacional. São projetadas com base em equipes, com menos hierarquia, com responsabilidade compartilhada e um equilíbrio de poder dinâmico, construído no próprio processo de decisão" (MOTTA,1991).

Os setores descentralizados são autônomos e independentes, mas tem a sua interdependência garantida através de valores compartilhados e sistema de comunicação intensivo. Coordenada no topo, a organização flexível possui redundância em muitas tarefas e caracteriza-se por redução do quadro gerencial intermediário. A organização se torna, desta forma, um conjunto de pequenas organizações interdependentes, onde a conexão entre as partes se dá através de intenso sistema de comunicação, em que todas as informações são distribuídas igualmente por todos os setores. "É chamada de organização modular, orgânica, celular, atomizada ou holográfica"(MOTTA,1991).

Diante do contexto atual, e das características de administração flexível apontadas por MOTTA (1991) e MÉDICI \& SILVA (1993), sentimo-nos motivadas a estudar a experiência administrativa vivenciada por um hospital filantrópico, da região metropolitana de Belo Horizonte, considerada inovadora em relação à participação dos funcionários e comunidade, à luz do referencial teórico sobre administração flexível. Para tal estabeleceu-se o seguinte objetivo: Identificar a percepção dos funcionários e representantes da comunidade sobre o modelo gerencial adotado no hospital.

\section{METODOLOGIA}

Trata-se de um estudo exploratório utilizando abordagem qualitativa, realizado no Hospital Sofia Feldman, Distrito Sanitário Norte de Belo Horizonte.

A escolha do campo de pesquisa se deu por ser campo de estágio curricular do curso de graduação em enfermagem, local de desenvolvimento de projetos de extensão da Escola de Enfermagem da Universidade Federal de Minas Gerais (UFMG), facilidade de acesso das pesquisadoras, abertura da instituição para desenvolvimento de pesquisas e por apresentar características inovadoras de gerência de serviço com participação de funcionários e da comunidade.

A Fundação de Assistência Integral à Saúde/ Hospital Sofia Feldman (FAIS/HSF), campo da pesquisa, tem como objetivo prestar assistência integral à saúde da mulher, da criança e do adolescente, através de equipes multiprofissionais.

Criado em 1982 pela Sociedade São Vicente de Paula, o Hospital Sofia Feldman (HSF) foi construído no bairro Tupi, $\mathrm{BH}$, em regime de mutirão.

A doação do terreno pela família Feldman, a participação ativa da comunidade do bairro e o idealismo de um grupo de Vicentinos foram a base de um trabalho voltado para o atendimento à criança a nível ambulatorial. Como não havia nenhum hospital localizado na região norte de Belo Horizonte, o serviço foi sendo ampliado gradativamente para a assistência à gestante, ao parto e internação conjunta em pediatria, mantendo, porém, o enfoque preventivo em todos os níveis de atendimento.

Atualmente a FAIS/HSF presta atendimento ambulatorial nas áreas de pré-natal, planejamento familiar, prevenção de câncer ginecológico, puericultura, controle de crianças de risco, vacinação e exames laboratoriais, entre outros. No que se refere à internação, tem capacidade instalada de 45 leitos, divididos entre maternidade e pediatria. É importante ressaltar que a instituição, buscando melhor recuperação do paciente e oportunidades para desenvolver um trabalho educativo, adotou o sistema de alojamento conjunto na maternidade e internação conjunta na pediatria.

Até 1986, o serviço sobreviveu apenas com recursos da comunidade. A partir deste ano passou a receber verbas do programa de Assistência Integral à Saúde (AIS) e, posteriormente, do Sistema Único de Saúde (SUS). Em 1988, foi transformado em Fundação de Assistência à Saúde/Hospital Sofia Feldman, por iniciativa de seus funcionários e participação comunitária.

O trabalho voluntário é organizado sistematicamente pela ACAU (Associação Comunitária de Amigos e Usuários do Hospital Sofia Feldman), que realiza reuniões periódicas para discutir as questões que envolvem a clientela e o hospital. Possui sala privativa no HSF para atendimento da clientela e levantamento de suas necessidades. Faz integração com as associações dos bairros vizinhos e outros serviços de saúde da região, além de atuar, também, na arrecadação de recursos financeiros e sensibilização da comunidade para doações de roupas e de alimentos.

A ligação entre a clientela e a direção do Hospital é feita através do OMBUDSMAN, membro da ACAU, que trabalha em sistema de rodízio colhendo dados da clientela através de um questionário para avaliação do serviço. Tal iniciativa foi baseada em experiências de várias empresas que colocam um funcionário para ouvir as reivindicações e queixas de seus clientes e levá-las à direção da instituição, para assim traçarem estratégias de melhoria do serviço. A presença do OMBUDSMAN é diária no hospital e ele tem acesso aos clientes, funcionários e a todas as dependências da instituição.

Outra preocupação da ACAU é a participação da MÃE SUBSTITUTA, mulher voluntária da comunidade, na internação de pediatria. Estas voluntárias auxiliam mães e outros acompanhantes das crianças, quando necessitam se ausentar do hospital e colaboram, ainda, no setor de costura do HSF. 
Para o gerenciamento da instituição foi criada a Comissão Técnica Administrativa (CTA), formada por representantes de vários setores/serviços do hospital, como enfermagem, médico, apoio-diagnóstico e terapia, manutenção e administração, que se reúne semanalmente para tomada de decisões, tendo como prioridade as necessidades da comunidade.

Como sujeitos da pesquisa elegeu-se funcionários que ocupam diferentes posições na estrutura organizacional, além de representantes da comunidade, buscando apreender a visão dos vários atores sociais sobre a administração da instituição. O número de entrevistas foi determinada pela repetição dos dados, ou seja, quando nenhuma informação nova estava sendo acrescentado encerrou-se a coleta de dados, o que ocorreu na 6 a (sexta) entrevista, talvez por se tratar de uma organização de pequeno porte e onde há participação significativa dos funcionários e membros da comunidade na vida organizacional. Assim, foram realizadas 06 (seis) entrevistas envolvendo pessoal administrativo, serviço social, pessoal de enfermagem e representantes da comunidade.

$\mathrm{O}$ instrumento de coleta de dados foi um roteiro de entrevista semi-estruturada que foi aplicado, pelas pesquisadoras, a cada um dos entrevistados, no próprio local de trabalho. Caso o entrevistado não discorresse claramente sobre a questão, formulava-se perguntas complementares, visando elucidar sua percepção.

Buscando-se captar as informações em sua totalidade, solicitou-se autorização dos entrevistados para gravação da entrevista. $\mathrm{O}$ anonimato dos respondentes e a utilização dos dados para fins científicos foram garantidos.

$\mathrm{Na}$ análise qualitativa dos dados as entrevistas gravadas foram transcritas e recortadas buscando-se extrair dos discursos as falas significativas referentes à forma de administração. Buscou-se compreender, através das falas dos sujeitos, a estrutura gerencial, as vantagens e problemas apresentados, o sistema de comunicação, a identificação do trabalhador com o modelo adotado e as formas de participação da comunidade.

\section{APRESENTAÇÃO E DISCUSSÃO DOS RESULTADOS}

Os depoimentos dos sujeitos, referentes a administração do hospital, foram submetidos a um tratamento qualitativo visando apreender os temas contidos em seus discursos. Emergiram das falas aspectos relacionados à forma de gestão adotada, integração dos funcionários e comunidade ao cotidiano do hospital, acesso a informações e perspectiva de participação indireta através dos representantes na CTA.

Buscando conhecer a visão dos funcionários e representante dos usuários a respeito da administração do hospital e partindo-se da análise dos depoimentos, identificou-se quatro categorias empíricas, ou seja, organização do serviço, comunicação, satisfação profissional e relação com a comunidade.

\subsection{Organização do serviço}

A maioria dos entrevistados mostrou ter alguma familiaridade com o tipo de gestão organizacional, em decorrência da participação no cotidiano de trabalho do hospital, destacando-se os relatos dos funcionários com maior tempo de serviço na instituição. Foi ressaltado o papel da CTA como órgão decisório superior da organização, composto pelas diversas categorias profissionais dos setores, conforme explicitado nos depoimentos abaixo:

\section{"Ë uma administração participativa, no CTA os representantes de vários setores tomam decisões referentes a instituição. Não é todo mundo participando toda hora. A direção do hospital também tem que tomar decisões ...o poder aqui passa pelo CTA principalmente pelo coordenador geral". E1}

"Acho este tipo de administração boa, tem muito contato com as pessoas, mais as vezes deixa a desejar... os problemas dos setores da enfermagem, são levados, para o CTA através do representante da enfermagem que traz a resposta para a gente. Quando surge um problema urgente é levado para o CTA e a resposta geralmente é rápida, dependendo do problema". E2

"É uma administração aberta para todos e sendo mais aberta as pessoas podem dar opiniões". E3

O aspecto mais ressaltado foi a participação dos funcionários na gestão do hospital, indiretamente, através dos representantes na CTA. Percebe-se que, por parte dos funcionários, há um sentimento de que "fazem parte da organização", são ouvidos e valorizados, além de reconhecerem a CTA como um órgão que dá mais agilidade às decisões. A participação e a agilidade nas decisões refletem uma tendência flexível de gestão que valoriza o trabalhador, suas opiniões e a capacidade de resposta, no curto prazo, para se adaptar às exigências ambientais.

Os funcionários reconhecem a importância da participação através dos representantes dos setores na CTA. De acordo com os entrevistados, os problemas cotidianos de trabalho, dependendo de sua complexidade e urgência, são levados ao coordenador de setor ou 
diretamente à CTA, que se empenha na resolução dos mesmos, o mais rápido possível, de forma a não provocar estrangulamento nos serviços oferecidos ou refletir negativamente em outros setores. Assim, os funcionários sentem mais liberdade para participar efetivamente e de maneira criativa no cotidiano da instituição.

De acordo com MENDONÇA (1987) a participação propicia efetivo reconhecimento dos indivíduos pelo grupo, satisfazendo-lhe, dessa forma, as necessidades humanas de autonomia, auto-realização e relacionamento humano. O pressuposto das diversas visões de administração participativa, é a identificação do conflito indivíduo-organização e a preconização da possibilidade de sua superação por meio da ação.

Apesar dos relatos referentes a participação dos funcionários na administração do hospital, através do CTA, percebe-se nos discursos a liderança de um profissional que vem atuando na instituição, desde a sua criação, tanto em atividades administrativas quanto clínicas. Este reconhecimento ocorre internamente no serviço e se estende à comunidade, conforme nos mostram os relatos do representante da ACAU e de um funcionário do hospital.

"A administração do serviço, principalmente a do Dr. ...é ótima .Ele tenta resolver os problemas do hospital ou dar soluções e instruções para a resolução do problema, caso você não consiga solucioná-lo... Ele sempre nos atende a qualquer hora". E4

"O atendimento do Dr. ... é muito bom. Ele tenta resolver os problemas e eu o ajudo na organização dos serviços. Se ele sair do hospital.....". E5

$\mathrm{Na}$ fala tanto do funcionário, quanto do representante da comunidade aparece a figura de um profissional que, na visão deles, é responsável pela continuidade da proposta de gestão. Esta dependência, se for generalizada pode constituir-se em ameaça para a continuidade do modelo adotado. As idéias e os valores, portanto, devem ser disseminados entre os demais membros da instituição, como forma de garantir a continuidade e o aperfeiçoamento da filosofia de trabalho em curso.

\subsection{Comunicação}

Considerando a comunicação como ferramenta fundamental para o aperfeiçoamento do processo de trabalho e produto final, os entrevistados apontam-na como essencial em todos os sentidos da hierarquia da instituição, seja internamente, na interdependência dos setores ou externamente na relação da organização com comunidade.
"A comunicação é diferente de outros tipos de administração porque as pessoas tem acesso às informações... É mais tranqüilo a partir do momento que você sabe dos problemas, sendo mais transparente a questão das dificuldades... No entanto, existe problemas com a comunicação, que não é repassada para os funcionários da forma como deveria ser". E1

"Entre os funcionários e a associação a comunicação é ótima. Através do OMBUDSMAN se busca levantar os problemas que o serviço enfrenta". E3

"No momento, a comunicação é informal, ocorre através de conversas, não havendo relatórios escritos há propostas de formalização do sistema de informação, para que ele seja mais efetivo... A falta de uma comunicação efetiva entre os funcionários técnicos gera problemas na administração”. E5

"Não fui informada em relação a administração como um todo. Só sei quem é minha chefe direta". E6

A comunicação em todos os sentidos da hierarquia da empresa, é uma característica essencial em qualquer proposta de gestão flexível (MÉDICI \& SILVA, 1993). Mesmo mantendo caráter informal, o que é desejável nos estágios iniciais, ela se torna uma ferramenta fundamental para integração entre os setores, reconhecimento e interpretação das demandas externas e para a integração dos novos empregados à organização.

Percebe-se, nos relatos, o reconhecimento da importância de um efetivo sistema de comunicação, para que as pessoas inseridas no hospital tenham acesso às informações de forma transparente, reconheçam as dificuldades, possam se relacionar bem com a comunidade assistida que auxilia o hospital em suas dificuldades mas também exerce um "certo controle social" dos serviços. Além disso, o caráter informal da comunicação que pode ser caracterizado como o primeiro embrião para a introdução das mudanças organizacionais, a serem sistematizadas após o experimento inicial, fogem, em parte, dos modelos tradicionais de gestão, que engessam as idéias antes de colocá-las em prática. Acreditamos, assim, que a integração dos setores e funcionamento da organização dependem em grande parte do sistema de comunicação adotado. Por se tratar de um hospital de pequeno porte, aberto à participação comunitária e dos funcionários, os primeiros passos já estão dados, cabe a partir de agora avaliar os resultados e fazer as correções necessárias. 


\subsection{Satisfação profissional}

Para MÉDICI \& SILVA (1993), a participação do trabalhador de forma criativa e inteligente, tem um papel determinante na organização do trabalho e nos resultados obtidos. Os entrevistados relatam que, quanto maior a participação e envolvimento dos funcionários com a instituição, maior o grau de satisfação dos mesmos. Percebe-se, nos relatos que o grau de satisfação no trabalho não está diretamente relacionada à questão financeira, pois segundo informações da gerência do hospital e dos próprios funcionários é comum o atraso de pagamentos e parcelamentos.

\section{"É bom a medida que você conhece a instituição... e aqui o funcionário usa a criatividade”. E1}

"O trabalho é reconhecido por parte do usuário... o enfermeiro tem resolutividade”. E2

"Eu me sinto satisfeito com o trabalho, e faço o que gosto. O meu setor é bem integrado e eu estou fazendo horas a mais para organizar o serviço que o funcionário da tarde não consegue fazer. Eu recebo estas horas em folga". E4

"Os coordenadores do CTA ganham pouco mais, mesmo assim eles se sentem motivados para o trabalho". E5

É de conhecimento geral na instituição que os funcionários têm informações a respeito das questões financeiras do hospital. Em épocas de crise, há atrasos ou parcelamento dos salários, de acordo com critérios pré-estabelecidos, que são conhecidos e aprovados por todos. Segundo os entrevistados este fato não afeta negativamente a motivação e a satisfação no trabalho e o conhecimento da filosofia e das dificuldades do hospital fortalece a idéia de co-responsabilidade dos funcionários, que é vista como uma forma de viabilizar o serviço.

\subsection{Relação com a comunidade}

O envolvimento com a comunidade possibilitou o desenvolvimento da instituição voltada para as necessidades reais da clientela. Percebe se uma valorização da comunidade por parte da CTA e demais funcionários e da comunidade em relação ao trabalho do hospital:

"Eu me sinto ótimo trabalhando aqui, e o meu trabalho é voluntário... Depois que a associação veio para cá a instituição melhorou muito, o contato com a comunidade é bom, a gente escuta o usuário e tenta mostrar que queremos ajudá-los. Cada dia tem um ombudsman, um de manhã e outro a tarde.A gente fica circulando no hospital e com isto nós conseguimos identificar os problemas do usuário”. E3

"Com a presença da associação de bairro melhorou o atendimento do hospital. Eles vieram para dar uma força. Eles tem ajudado a gente a resolver os problemas". E4

"A comunidade esta fazendo um trabalho muito grande em relação a doações através da associação comunitária .Estas doações são utilizadas conforme a necessidade do usuário e da instituição... As doações chegam através de roupas, dinheiro e alimentos". E5

"Depois que a associação veio para cá a instituição melhorou muito... O contato com a comunidade é bom. ... a gente escuta o usuário e tenta mostrar que queremos ajudá-los”. E3

Na relação com a comunidade a instituição busca conhecer as falhas existentes no atendimento e propõe soluções viáveis, conjuntamente, para melhorar a assistência, demonstrando estar em sintonia com as necessidades da comunidade na qual está inserida. Por outro lado, a comunidade responde prontamente às necessidades explicitadas pela instituição, através de campanhas de arrecadação de roupas e alimentos, bem como distribuição de carnês para doações em espécie, de acordo com a disponibilidade financeira do doador.

Esta parceria, a nosso ver, representa um grande avanço naquilo que diz respeito ao atendimento das reais necessidades da clientela, que através de seus representantes voluntários trazem suas demandas, apontam falhas, oferecem sugestões e colaboram com o trabalho do hospital. Significa, também, um aprendizado para os profissionais que passam a lidar de forma natural com o usuário dentro do serviço, uma tendência contemporânea de gestão das organizações, onde o cliente ocupa lugar de destaque.

\section{CONSIDERAÇÕES FINAIS}

Neste estudo constatou-se que FAIS/HSF, apresenta algumas características da administração flexível tais como: envolvimento e participação dos funcionários, satisfação profissional, sensibilidade para atender às exigências da clientela, sistema de comunicação avançado em relação a outras instituições de saúde e participação ativa da comunidade na gestão e 
no trabalho cotidiano da organização.

Embora a proposta da instituição seja de gerência flexível, com valores compartilhados e sistema de comunicação intenso, que vem sendo colocados em prática com competência, sua organização e seu funcionamento ainda são permeados por idéias preconizadas pela gerência clássica, ou seja, divisão do trabalho nos moldes tradicionais, chefias intermediárias, por categoria profissional, que definem o trabalho a ser realizado pelos menos qualificado, que são características das formas tradicionais de gerência dos serviços de saúde.

No entanto, através da sensibilização das equipes interdisciplinares, mobilização dos trabalhadores e dos usuários, sistematização das experiências já consolidadas e continuidade do envolvimento da comunidade, a instituição terá condições de avançar e consolidar o modelo de administração flexível, inaugurando uma nova forma de gestão para os Serviços de Saúde.

\section{FOUNDATION OF INTEGRAL HEALTH CARE: AN EXPERIENCE OF FLEXIBLE ADMINISTRATION?}

The purpose of the present study was to verify the correspondence between the administrative experience of the Hospital "Sofia Feldman" and the theory on flexible management proposed by MOTTA (1991) and MÉDICI \& SILVA (1993). It also described innovation elements for institutional integration with the community, such as the substitute mother, ombudsman and systematic voluntary work, done by Community Association of Friends and Users of Sofia Feldman Hospital. Data were collected with a semi-structured interview, applied to employees of differents sectors, aiming at knowing their perception about the administrative model used. The flexible administration characteristics of the hospital were evidenced, however authors found elements of classical administration.

KEY WORDS: hospital administration

\section{FUNDACIÓN DE ASISTENCIA INTEGRAL A LA SALUD/HOSPITAL SOFIA FELDMAN: UNA EXPERIENCIA DE ADMINISTRACIÓN FLEXIBLE?}

El presente trabajo tuvo como objetivo trazar un paralelo entre la experiencia administrativa del Hospital Sofia Feldman y la teoria de gerencia flexible propuesta por MOTTA (1991) y MEDICI\& SILVA (1993). Describe, también, elementos innovadores de integraçión de la instituición com la comunidad: madre sustituta, ombdsman y trabajo voluntario sistematizado de la Associación Comunitaria de los Amigos y Usuarios del Hospital Sofia Feldman. La recolección de los dados fue realizada a través de una guía de entrevista semi-estructurada aplicada al modelo gerencial adoptado. Las informaciones coletadas puntualizan características de administración flexible en el hospital, pero, intercalada de trazos de gerencia clásica.

TÉRMINOS CLAVES: administración hospitalaria

\section{REFERÊNCIAS BIBLIOGRÁFICAS}

01. MÉDICI, A.C; SILVA, P.L.B. Administração flexível: introdução às novas filosofias de gestão. Rev.Adm.Publica, Rio de Janeiro, v. 27, n.3, p.26-35, jul/set. 1993.
02. MENDONÇA, L.C. de. Participação na organização: uma introdução aos seus fundamentos, conceitos e formas. São Paulo: Atlas, 1987. $143 \mathrm{p}$.

03. MOTTA, P.R. Gestão contemporânea: a ciência e a arte de ser dirigente. 2. ed. Rio de Janeiro: Record, $1991.256 \mathrm{p}$. 